\title{
Capacidade de sorção de materiais inconsolidados residuais da Formação Botucatu, região de São Carlos (SP), Brasil
}

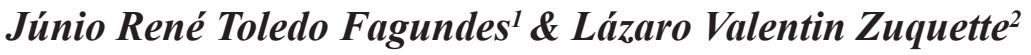

\begin{abstract}
Resumo O transporte de poluentes em meio geológico poroso depende de diversas características intrínsecas dos materiais geológicos (rochas e materiais inconsolidados), dentre elas a sorção, que é o principal fator para a avaliação dos processos de atenuação e retardamento dos poluentes, assim como da recuperação natural e está diretamente relacionada à carga eletrostática dos componentes minerais e dos restos orgânicos. As condições de sorção dos materiais inconsolidados residuais da Formação Botucatu foram estudadas considerando uma solução multicomponente de $\mathrm{Na}^{+}, \mathrm{K}^{+}, \mathrm{Zn}^{++}$e $\mathrm{Cu}^{++}$com concentração total variando de 200 a 1000 ppm, por meio de ensaio em lote. Verificou-se que as isotermas de sorção obtidas experimentalmente para o $\mathrm{Cu}^{++}$ são representadas matematicamente, de maneira mais adequada, pelas equações de Freundlich e Langmuir I, enquanto que para o $\mathrm{K}^{+}$e o $\mathrm{Zn}^{++}$pela isoterma linear.
\end{abstract}

Palavras-chave: sorção, Formação Botucatu, ensaios de equilíbrio em lote, São Carlos, Brasil.

\begin{abstract}
Sorption capacity of the residual unconsolidated material of Botucatu Formation - São Carlos region (state of São Paulo), Brazil. The pollutant transport through porous geological materials depends on intrinsic characteristics as the sorption. It is the main environmental aspect to evaluate attenuation and retardation of the pollutants, as well as the natural remediation capacity. Sorption is directly related to electrostatic change of the minerals, organic matter, oxides and hydroxides. A study to assess the sorption characteristics of the sandy residual unconsolidated material of the Botucatu Formation was developed using a multi component solutions of $\mathrm{NaCl}, \mathrm{KCl}, \mathrm{ZnCl}_{2}$ and $\mathrm{CuCl}_{2} \cdot \mathrm{H}_{2} \mathrm{O}$ with total concentration varying between 200 and $1000 \mathrm{ppm}$. The Langmuir I and Freundlich equations represented better the sorption behavior of $\mathrm{Cu}^{++}$, and the linear approximation was more adequate to represent $\mathrm{K}^{+}$and $\mathrm{Zn}^{++}$for two unconsolidated materials.
\end{abstract}

Keywords: sorption, Botucatu Formation, batch test, São Carlos, Brazil.

INTRODUÇÃO Diversos são os usos que geram ou utilizam produtos químicos que entram em contato com o meio ambiente, tais como o emprego de fertilizantes e pesticidas na agricultura e a disposição de resíduos. Tais usos caracterizam-se como fontes de poluição que podem ser classificadas como difusas ou pontuais, dependendo da escala. Com freqüências e volumes variados, e muitas vezes sem critérios técnicos, essas fontes são normalmente instaladas sobre materiais inconsolidados, que constituem um meio poroso por onde se processa a infiltração das águas oriundas de chuvas, de irrigação e mesmo das fontes de poluentes. Desta forma, os compostos químicos presentes nestas fontes são solubilizados e os íons transportados até a zona saturada.

Entretanto, o abastecimento de água, residencial ou industrial, se dá por explotação direta das águas subterrâneas ou por captação superficial em canais de drenagem, que são mantidos pelas águas subterrâneas quando afloram na forma de fontes naturais. Consequentemente, a manutenção da qualidade hídrica dos corpos subsuperficiais é um alvo que deve ser permanentemente visado em estudos ambientais, principalmente por sua dinâmica longa ao contrario de outros componentes ambientais. Para tanto, a compreensão e a caracterização dos aspectos relativos ao transporte de poluentes em meios porosos são de fundamental importância, e depende do conhecimento sobre o comportamento dos poluentes em subsuperfície e sua interação com os materiais sólidos (minerais e matéria orgânica) constituintes dos materiais geológicos. Este conhecimento é fundamental para que estudos de previsão de contaminação das águas subsuperficiais (zonas saturadas e vadosa) sejam desenvolvidos por meio de modelação com métodos matemáticos numéricos. O sistema constituído por partículas sólidas minerais e de matéria orgânica com uma solução liquida com poluentes é denominado de sistema adsorção sólido-soluto.

Os principais mecanismos que afetam o transporte dos solutos neste sistema são: a advecção, a dispersão hidrodinâmica, a sorção, o decaimento de primeira ordem e reações biogeoquímicas. A advecção ocorre em função de um fluxo hidráulico, sendo diretamente relacionada à velocidade de percolação, e é considerada como a principal responsável pela evolução da frente de contaminação. Por outro lado, a dispersão hidrodinâmica engloba a dispersão mecânica e a difusão 
molecular. Enquanto esta trata do transporte causado pelos diferentes gradientes de concentração de espécies químicas do meio, a outra está relacionada ao espalhamento longitudinal e transversal à direção principal de fluxo, gerando uma diluição gradual dos poluentes.

Em casos de solutos não reativos, os íons migram na mesma velocidade do solvente. Nestes casos, nenhum mecanismo de atenuação é verificado, bastando, consequentemente, a determinação dos coeficientes de dispersão hidrodinâmica (Freeze \& Cherry 1979). Entretanto, a ocorrência destes é normalmente tida como exceção. O que se verifica na maioria dos casos é a existência de interações químicas e físicas entre a fase líquida (solução) e as partículas do solo, notadamente os argilominerais, os óxidos e hidróxidos e a matéria orgânica. Tais interações reunidas definem a sorção, que é um termo comum no caso da relação entre fases sólida e líquida (concomitantes), e refere-se à transferência geral de material da fase líquida para as interfaces da fase sólida. Este termo é utilizado devido às dificuldades para distinguir entre os mecanismos de adsorção (física e química) e precipitação (Yong et al. 1992).

Considera-se precipitação quando existe a transferência de soluto da fase aquosa para a superfície da fase sólida, resultando em uma nova substância, com uma nova fase sólida cristalina. O processo de precipitação ocorre em 2 fases, de nucleação e de crescimento da partícula, e pode se formar na superfície das partículas ou nos poros interpartículas. $\mathrm{O} \mathrm{pH}$ do material geológico e da fase líquida, o Eh, e a concentração dos contaminantes são os principais controladores deste processo.

Quando líquidos poluídos percolam os materiais geológicos parte dos íons e/ou moléculas podem ser adsorvidos pelas partículas que constituem os materiais geológicos sejam minerais ou materiais orgânicos. Tal processo ocorre até uma condição denominada de equilíbrio de absorção, e poderá modificar-se quando um ou mais dos atributos controladores $(\mathrm{pH}$, pressão e temperatura) sofrerem alteração. A relação entre a massa de soluto adsorvida e a concentração em equilíbrio é denominada de isoterma de adsorção. Entende-se que uma isoterma descreve a relação da concentração de um soluto entre 2 fases separadas em equilíbrio, em uma temperatura constante. Assim, uma isoterma de sorção expressa a relação entre a quantidade de vapor ou soluto adsorvido como uma função da concentração de equilíbrio do vapor ou soluto, sem referência a mecanismos. Comumente uma isoterma de sorção é enquadrada em quatro categorias de acordo com Giles et al. (1974) como isotermas $\mathrm{S}$ (em forma sigmoidal), L (do tipo Langmuir), H (alta afinidade) e C (partição constante), e subdivididas em 4 subgrupos (Fig. 1). Esta classificação está baseada nas inclinações iniciais e nas curvaturas. Matematicamente estas isotermas podem ser descritas como equações do tipo funções racionais (normalmente são quocientes de polinômios) compreendendo as equações de Langmuir, Langmuir-two site, Brunauer-Emmett-Teller e a de Farley-Dzombakmorel. As equações potenciais normalmente consideram funções de potências e contemplam as equações

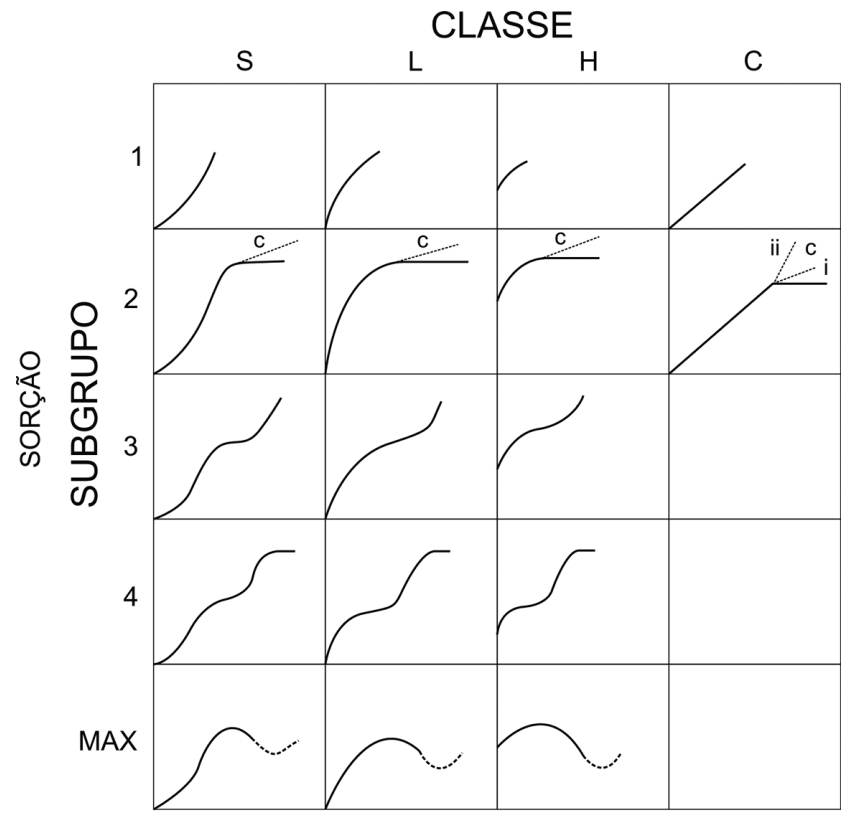

Figura 1 - Categorias e subgrupos de isotermas de sorção segundo Giles et al. (1974).

de Freundlich, Geral de Langmuir-Freundlich, Geral de Freundlich, a de Tóth, a de Redlich-Peterson e de Aranovich-Donhoue. E as transcendentais, que são equações desenvolvidas para representar isotermas de condições específicas.

Dentre as 4 categorias a $\mathrm{L}$ e a $\mathrm{C}$ são muito usadas para materiais geológicos, sendo que a L é representada em termos matemáticos simplificados como equações de Langmuir ou Freundlich e a C, como linear. Segundo Hinz et al. (1974) e Hinz (2001) a adequada descrição dos dados de sorção em apropriadas equações é fundamental, pois permite obter bons resultados quando modelações de transporte de poluentes são desenvolvidas para a previsão de fluxo de poluentes em materiais geológicos.

A taxa de adsorção está relacionada à carga eletrostática das partículas que constituem os materiais geológicos, e em condições de clima tropical são geralmente variáveis (positiva e negativa) resultantes da assembléia mineralógica e do $\mathrm{pH}$. Para um determinado valor de $\mathrm{pH}$, o balanço das cargas superficiais variáveis $\left(\mathrm{s}_{\mathrm{V}}\right)$ pode ser nulo. Quando isto ocorre, este $\mathrm{pH}$ é denominado ponto de carga zero ( $\mathrm{pH}_{0}$ ou $\left.\mathrm{PCZ}\right)$, enquanto o ponto de carga líquida zero (PCLZ) é definido quando a soma das cargas variáveis $\left(\mathrm{s}_{\mathrm{V}}\right)$ e permanentes $\left(\mathrm{s}_{\mathrm{p}}\right)$ é igual à zero. Nestas condições, o $\mathrm{pH}_{0}$ somente equivalerá ao PCLZ se a componente $\mathrm{s}_{\mathrm{p}}$ for igual à zero.

A sorção pode ser obtida por diferentes procedimentos, como através de ensaios de coluna, utilizandose amostras indeformadas, ou ainda através de ensaios em lote (batch test) em amostras deformadas ou por meio de relações empíricas. Dentre os ensaios conhecidos, o em lote é o mais freqüente, por permitir maior controle das condições físico-químicas (pH, Eh, etc).

Ensaios de equilíbrio em lote são frequentemen- 
te utilizados em laboratório para a obtenção de parâmetros de sorção. Consiste basicamente na colocação de uma massa de solo em contato e agitação contínua com soluções contaminantes em concentrações variadas. Podem ser realizados de duas maneiras: (1) variandose a concentração de soluto em solução e mantendo-se constante a massa de solo ou (2) deixando-se invariável a concentração e utilizando-se diferentes razões solo/ solução (Roy et al. 1992). Decorrido o tempo necessário para que o equilíbrio físico-químico se estabeleça, segue-se a etapa das análises do extrato aquoso, sendo a quantidade da espécie química sorvida pelo solo determinada pela equação (1):

$$
S=\frac{\left(C_{0}-C_{e}\right) \cdot V \cdot 1000}{M}
$$

Sendo,

$S$ - massa de soluto adsorvido por unidade de massa de sólido $[\mu \mathrm{g} / \mathrm{g}]$;

brio $[\mathrm{mg} / \mathrm{l}]$

$C_{0}$ - concentração inicial da solução [mg/l];

$C_{e}$ - concentração final da solução em equilí-

$V$ - volume da solução utilizada no ensaio [1];

$M$ - massa de sólidos (solo) [g].

Diante do contexto, foi desenvolvido um estudo dos materiais inconsolidados residuais da Formação Botucatu da região de São Carlos, estado de São Paulo, no sentido de avaliar a capacidade de sorção destes materiais frente a um contaminante multi-iônico, representado por uma solução aquosa de cloretos de $\mathrm{Na}^{+}, \mathrm{K}^{+}$, $\mathrm{Zn}^{++}$e $\mathrm{Cu}^{++}$. A escolha destes materiais geológicos se deu em função da importância dos arenitos da Formação Botucatu como reservatório de águas subsuperficiais. No Brasil alguns estudos sobre sorção vêm sendo desenvolvidos para analises referentes à fertilidade de solos, e dentre eles tem-se os de Nascimento \& Fontes (2004), Barinzon et al. (2005), Santos et al. (2006), Souza et al. (2006) e Pierangeli et al. (2007).

Representação matemática das isotermas de sorção Existem 2 grupos diferentes de modelos que podem ser considerados na modelação da sorção: os empíricos e os químicos.

Dispondo-se em um diagrama cartesiano os valores de $S$ (massa de soluto adsorvido por unidade de massa de sólido $[\mu \mathrm{g} / \mathrm{g}])$ e $C_{e}$ concentração final da solução em equilíbrio [mg/l]), tem-se um gráfico denominado isoterma de sorção ou adsorção, que caracteriza o comportamento sorcivo do material geológico ante a um elemento químico em solução. A modelagem do fenômeno sorcivo é útil, portanto, como uma ferramenta de previsão, e pode ser obtida através do ajuste de parâmetros de modelos matemáticos conhecidos aos dados experimentais. Neste grupo o modelo matemático é escolhido após a obtenção dos dados de sorção por meios experimentais, de maneira que estes apresentem boa concordância entre si.
CONDIÇÃO PARA SOLUÇÃO MONOCOMPONEN$T E$ A partir da isoterma obtida é fundamental selecionar uma representação matemática, e dentre as equações mais conhecidas destacam-se as descritas a seguir:

\section{Linear}

O modelo de isoterma linear prevê a sorção de soluto em concentrações infinitamente crescentes, e é representado pela equação 2 :

$$
S=K_{d} \cdot C_{e}
$$

Sendo $K_{d}$ o coeficiente de distribuição expresso pelo coeficiente angular da reta $[\mathrm{l} / \mathrm{g}]$.

Como o solo possui capacidade limitada de sorção, o modelo de isoterma linear se mostra muitas vezes inadequado. Porém, a adoção deste modelo pode ser interessante quando são analisadas baixas concentrações.

\section{Freundlich}

A isoterma gerada a partir da modelagem proposta por Freundlich surgiu como uma alternativa para melhor representar os processos sorcivos do solo que se apresentam curvilíneos nos gráficos $S \times C_{e}$. A relação matemática que expressa a isoterma de Freundlich tem a forma da equação 3 :

$S=K_{f} \cdot C_{e}^{N}$

Sendo $K_{f}$ o coeficiente de partição de Freundli$\mathrm{ch}\left[\mathrm{cm}^{3} / \mathrm{g}\right]$ e $N$ o coeficiente exponencial de Freundlich. Este último especifica o tipo de sorção: quando $N>1$ a sorção é dita favorável; quando $N<1$, desfavorável; e quando $N=1$ a sorção se iguala ao modelo linear.

A transformação da equação acima para a forma logarítmica permite a obtenção destes parâmetros por meio de regressão representada pela equação 4 .

$$
\log S=N \cdot \log C_{e}+\log K_{f}
$$

Desta forma, $\mathrm{N}$ torna-se o coeficiente angular da reta e o $\log K_{f}$ o intercepto no eixo das ordenadas de um diagrama $(\log S) \times\left(\log C_{e}\right)$.

\section{Langmuir}

Segundo Langmuir, a fenômeno de sorção pode ser expresso pela seguinte equação 5 :

$$
S=\frac{S_{m} \cdot b \cdot C_{e}}{1+b \cdot C_{e}}
$$

Sendo $S_{m}$ a quantidade máxima de soluto adsorvida pelo solo $[\mu \mathrm{g} / \mathrm{g}]$ e $b$ uma constante de adsorção relacionada à energia de ligação $\left[\mathrm{cm}^{3} / \mu \mathrm{g}\right]$.

Os parâmetros $S_{m}$ e $b$ são obtidos via procedimentos de linearização: Langmuir I (equação 6) e Langmuir II (equação 7). 


$$
\begin{aligned}
& \frac{C_{e}}{S}=\frac{1}{S_{m} \cdot b}+\frac{C_{e}}{S_{m}} \\
& \frac{1}{S}=\frac{1}{b \cdot S_{m} \cdot C_{e}}+\frac{1}{S_{m}}
\end{aligned}
$$

No procedimento para Langmuir I, $\left(1 / S_{\text {m }}\right)$ e (1/ $\left.S_{m} \cdot b\right)$ correspondem, respectivamente, ao coeficiente angular da reta e ao intercepto da reta no eixo das ordenadas de um diagrama $\left(C_{e} / S\right) \times\left(C_{e}\right)$. Do mesmo modo, para Langmuir II, $\left(1 / b . S_{m}\right)$ e $\left(1 / S_{m}\right)$ representam o coeficiente angular da reta e o intercepto da reta no eixo das ordenadas de um diagrama $(1 / S) \times\left(1 / C_{e}\right)$.

\section{Isoterma Langmuir - Two-site}

Esta equação representa condições onde existem locais para ligação dos íons com diferentes níveis de energia de ligação. A observação desta condição se dá quando se elabora um gráfico com os resultados experimentais na forma $C_{e} / S$ contra $C_{e}$, e deste procedimento observase que a linha de tendência apresenta dois segmentos de retas, representados pela equação 8 :

$$
\frac{S}{C_{e}}=\frac{S_{m 1} \cdot b_{1}}{1+b_{1} \cdot C_{e}}+\frac{S_{m 2} \cdot b_{2}}{1+b_{2} \cdot C_{e}}
$$

\section{Sendo:}

$C_{e}$ - concentração da solução em equilíbrio $(\mathrm{mg} / \mathrm{l})$,

$S$ - quantidade adsorvida ( $\mu \mathrm{g}$ de poluente /g de material geológico),

$b_{1}$ - energia de ligação do local tipo 1 ,

$S_{m l}$ - quantidade máxima de soluto que pode ser adsorvido no local tipo 1 ,

$b_{2}$ - energia de ligação do local tipo 2 , e

$S_{m 2}$ quantidade máxima de soluto que pode ser adsorvido no local tipo 2 ,

CONDIÇÃO PARA SOLUÇÃO MULTICOMPONENTE Para o caso de modelos de sorção multicomponentes destacam-se duas adaptações das equações monocomponentes de Langmuir e Freundlich.

\section{Tipo Langmuir - competição}

Este modelo foi apresentado por Murali \& Aylmore (1983) segundo a equação 9:

$$
S_{i}=\frac{\mathrm{Sm}_{i} \cdot b_{i} \cdot C_{i}}{1+\sum_{j} b_{j} \cdot C_{j}}
$$

Sendo:

$C_{i}$ - Concentração do cátion em solução,

$S_{i}$ - Quantidade de soluto adsorvido por unidade de adsorbente,

$S_{m}$ - parâmetro relativo à adsorção máxima,

$b_{i}^{m}$ - Parâmetros de afinidade de Langmuir,
De acordo com Van Riemsdijk et al. (1985) $K_{i}$ é proporcional a exp (-qi/RT), com qi representando a variação da energia livre de adsorção das espécies iônicas i.

Considerando uma competição entre dois cátions, têm-se as equações 10 e 11:

$$
\frac{1}{K_{d}}=\frac{1}{\left(\mathrm{Sm}_{i} \cdot b_{i}\right)}+\frac{C_{i}}{\mathrm{Sm}_{i}}+\frac{1}{\mathrm{Sm}_{i}} \cdot \frac{b_{j}}{b_{i}} \cdot C_{j}
$$

$$
\frac{1}{S_{i}}=\frac{1}{\mathrm{Sm}_{i}}+\left(\frac{1}{b_{i} \cdot \mathrm{Sm}_{i}}\right) \cdot \frac{1}{C_{i}}+\left(\frac{b_{j}}{b_{i} \cdot \mathrm{Sm}_{i}}\right) \cdot \frac{C_{j}}{C_{i}}
$$

Quando se considera a competição entre 3 cátions, a equação 12 representa as relações:

$$
\frac{1}{S_{i}}=\frac{1}{\mathrm{Sm}_{i}}+\left(\frac{1}{b_{i} \cdot \mathrm{Sm}_{i}}\right) \cdot \frac{1}{C_{i}}+\left(\frac{b_{h}}{b_{i} \cdot \mathrm{Sm}_{i}}\right) \cdot \frac{C_{h}}{C_{i}}+\left(\frac{b_{j}}{b_{i} \cdot \mathrm{Sm}_{i}}\right) \cdot \frac{C_{j}}{C_{i}}
$$

onde $C_{i}, C_{h}$ e $C_{j}$ são variáveis referentes às concentrações dos cátions.

\section{Modelo de Freundlich ampliado}

A equação 13 é valida para uma condição de monocomponente.

$S_{i}=K \cdot C_{i}^{M}$

Porém, Van der Zee \& van Riemsdijk (1985) propôs a inclusão de algumas variáveis como o $\mathrm{pH}$ e o carbono orgânico (oc) na equação 13 , modificando-a para a equação 14 :

$$
S_{i}=K^{*} \cdot\left(H^{+}\right)^{a} \cdot(o c)^{b} \cdot C_{i}^{M}
$$

tendo $\mathrm{K}^{*}$, a e b como constantes da equação.

Elzinga et al. (1999) propôs uma linearização conforme a equação 15 ,

$$
\log S_{i}=\log K^{*}+M \cdot \log C_{i}
$$

onde

$$
\log K^{*}=\beta_{0} \cdot \sum \beta_{i} \cdot \log X_{i}
$$

com $i=1$ até $\mathrm{M}$, sendo:

$K^{*}, a, b$ e $c$ são constantes da equação,

$X_{i}$ relativo a uma propriedade experimental do solo, $\beta_{i}$ é um coeficiente de regressão relacionado ao solo ou solução, e $\beta_{o}$ é uma constante de regressão. 
A equação 16 tem seu emprego para uma competição entre 2 cátions.

$$
S_{i}=K^{*} \cdot C_{i}^{M} \cdot C_{j}^{N}
$$

Quando se insere o $\mathrm{pH}$ e o valor de carbono orgânico (oc) é mantido constante para cada material geológico, tem-se a equação 17 :

$$
S_{i}=K^{*} \cdot\left(H^{+}\right)^{a} \cdot C_{i}^{M} \cdot C_{j}^{N}
$$

MATERIAIS E MÉTODOS O estudo foi desenvolvido de acordo com as fases contidas no fluxograma da figura 2, e de acordo com os aspectos fundamentais que devem ser considerados para a realização do ensaio em lote, citados por Zuquette et al. (2008), a saber:

1 - As condições físico-químicas dos materiais inconsolidados e as suas variações no decorrer do ensaio,

2 - As variações do comportamento das soluções aquosas em função das concentrações, $\mathrm{pH}$, Eh e proporções das misturas,

3 - Os métodos para determinação dos componentes químicos e os critérios de diluição, visto que erros ínfimos podem gerar erros em cadeia com magnitudes grandes,

4 - Avaliações prévias das condições físico-químicas das soluções aquosas e dos materiais geológicos no sentido de prever problemas de reações no decorrer do ensaio,

5 - As variações de temperatura devem ser controladas, pois pequenas mudanças afetam significativamente os resultados, por afetar a cinética das reações e por provo- car taxas variadas de evaporação da porção liquida,

6 - Para materiais geológicos laterizados, é fundamental a preparação de um conjunto de amostras, em paralelo, com quantidade suficiente para um ensaio de granulometria, no sentido de avaliar a estabilidade dos agregados durante o ensaio em lote, e

7 - Para um maior controle do ensaio em lote é aconselhável que seja preparada para cada condição (sólidos + componente químico) no mínimo 4 amostras, sendo 2 para avaliações intermediárias e 2 para as medidas finais.

Etapas $1^{\text {a }}$ - A coleta dos materiais inconsolidados residuais da Formação Botucatu foi feita em três locais distintos na região de São Carlos (SP) representando uma distribuição espacial e diferentes tipos de ocupação (pastagem, mata e agricultura), com vista a obter resultados que possam representar esta variabilidade (materiais $1,2 \mathrm{e}$ 3). Sendo assim, as amostras foram obtidas de tal maneira a evitar anomalias e presença de matéria orgânica que não são encontradas em profundidades maiores que 1 metro.

$2^{\mathrm{a}}$ - Ensaios clássicos da geotecnia foram realizados em laboratório para a caracterização física dos materiais, tais como granulometria conjunta e massa específica dos sólidos (ABNT 1984). Além do mais, devido à complexidade de reações envolvidas quando da interação solo/solução, caracterizações físico-químicas tornam-se necessárias nos estudos de contaminação. Sendo assim, as amostras foram também submetidas a ensaios para a determinação da capacidade de troca catiônica (CTC), superfície específica (SE), $\Delta \mathrm{pH}$ e ponto de carga zero $\left(\mathrm{pH}_{0}\right)$ de acordo com a proposição teórica de Singh \& Uehara (1988), seguindo metodologia apresentada em Camargo et al. 1986.

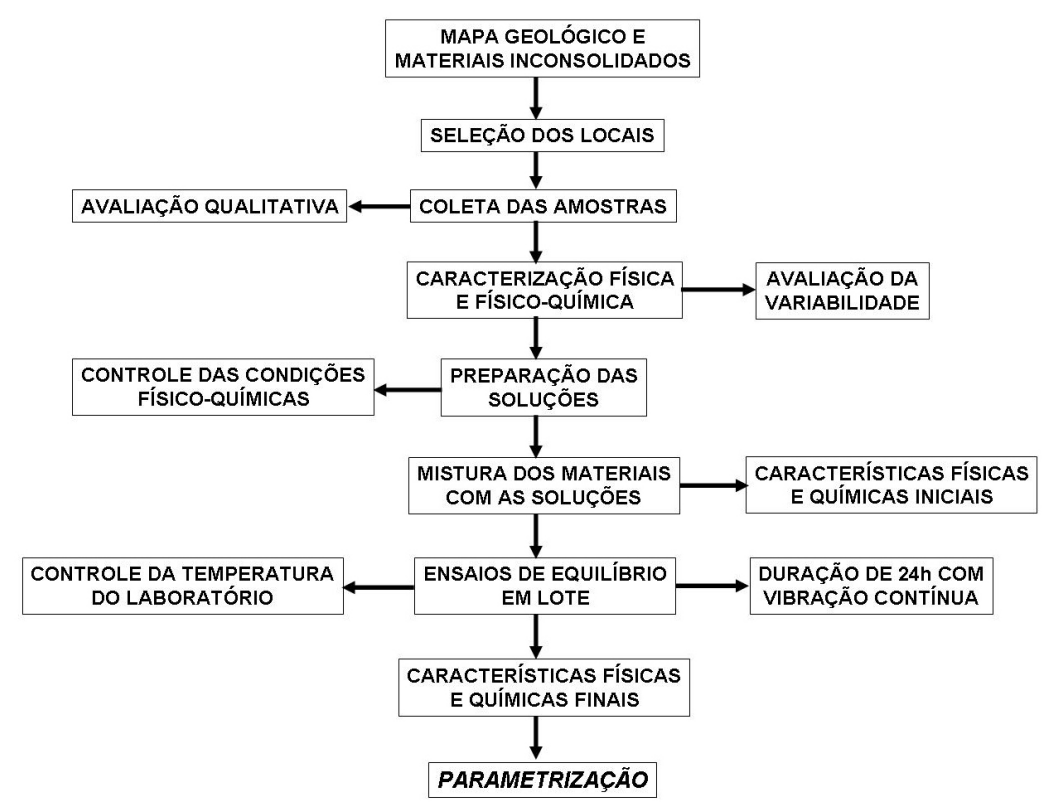

Figura 2 - Fluxograma seqüencial das etapas executadas no decorrer do estudo. 
$3^{\mathrm{a}}$ - Os ensaios de equilíbrio em lote seguiram os procedimentos que constam em Roy et al. (1992). O uso de soluções multi-iônicas de $\mathrm{Na}^{+}, \mathrm{K}^{+}, \mathrm{Zn}^{++}$e Cu${ }^{++}$deve se a condição da freqüência destas em fontes de poluição difusa e/ou pontual na região. Baseando-se em experiência anterior e em trabalhos como os de Leite (2001), a razão solo/solução e o tempo de equilíbrio (agitação contínua) adotado foram de 1:5 e 24 horas, respectivamente. Desta forma, para os três materiais pesquisados, foram utilizados 9 frascos com cerca de $20 \mathrm{~g}$ de solo e $100 \mathrm{ml}$ de solução.

$4^{\mathrm{a}}$ - Antes e após o tempo de vibração dos frascos, o controle dos parâmetros físico-químicos das suspensões ocorreu mediante registros dos valores de $\mathrm{pH}$, potencial redox (Eh) e condutividade elétrica (CE), que auxiliaram a interpretação dos resultados.

$5^{\mathrm{a}}$ - As determinações das concentrações iniciais e de equilíbrio foram realizadas com a utilização de um fotômetro de chama para os cátions $\mathrm{Na}^{+}, \mathrm{K}^{+}$, e de um espectrofotômetro para o $\mathrm{Zn}^{++}$e o $\mathrm{Cu}^{++}$.

$6^{\mathrm{a}}$ - Diante destes dados, a sorção pôde ser avaliada segundo a equação (1), que permitiu a obtenção das isotermas para os materiais inconsolidados dos 3 locais. Por fim, a parametrização dos efeitos sorcivos (isotermas) seguiu o método dos modelos descritos no item Materiais e Métodos.

CARACTERIZAÇÃO DOS MATERIAIS INCONSOLIDADOS A Formação Botucatu constituída por arenitos silicificados no topo e friáveis na base ocorre em toda a porção sul e em parcelas da sudeste e centro oeste do Brasil, aflorando como escarpas (arenitos silicificados) e relevo plano (arenitos friáveis), sendo que na segunda ocorrem zonas de recarga e descarga. Normalmente estão recobertos por um pacote de materiais inconsolidados residuais com espessuras variando da ordem de metro até superiores a $10 \mathrm{~m}$, podendo atingir valores superiores a 20 metros em alguns locais. No estado de São Paulo a região de afloramento encontra-se representada na figura 3 , e a área de estudo situa-se próxima à cidade de São Carlos. Os mapas do substrato rochoso e de materiais inconsolidados realizados por Zuquette \& Palma (2004) permitiram a seleção dos locais para a extração das amostras deformadas e indeformadas. As diferentes etapas do estudo estão esquematicamente representadas na figura 2 . O estudo dos materiais inconsolidados é de grande importância, visto que a recarga das águas subsuperficiais e a inserção de poluentes de dá a partir da superfície dos terrenos, portanto percolando estes materiais inconsolidados até atingir as diferentes profundidades.

A tabela 1 apresenta os resultados obtidos das caracterizações físicas e físico-químicas a que foram submetidos os materiais geológicos dos três locais amostrados. Embora os resultados apresentem-se bastante próximos para os materiais geológicos estudados, nota-se uma diferença no percentual de argila para o do local 2 quando comparadas às análises granulométricas feitas com e sem defloculante. Esta diferença pode ser um indicativo da presença de óxidos ou hidróxidos na amostra, conferindo a ela certo grau de cimentação entre os argilominerais e os grãos de quartzo.

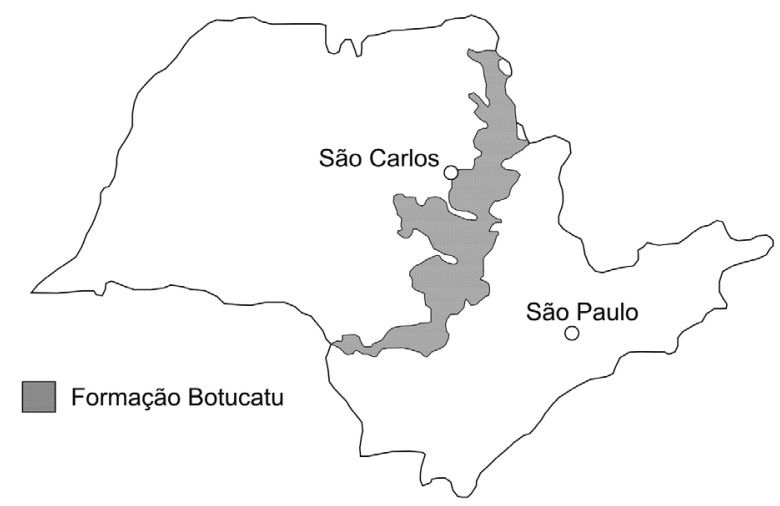

Figura 3 - Afloramento da Formação Botucatu e localização da área de estudo (Fonte: Zuquette \& Palma 2004).

Tabela 1 - Características físicas e físico-químicas dos materiais estudados.

\begin{tabular}{|c|c|c|c|}
\hline PROPRIEDADE & $\begin{array}{c}\text { Local } \\
1\end{array}$ & $\begin{array}{c}\text { Local } \\
\quad 2\end{array}$ & $\begin{array}{c}\text { Local } \\
3\end{array}$ \\
\hline Massa específica dos sólidos, $\rho_{\mathrm{s}}\left(\mathrm{g} / \mathrm{cm}^{3}\right)$ & 2,650 & 2,659 & 2,677 \\
\hline \multicolumn{4}{|l|}{ Granulometria com defloculante (\%) } \\
\hline $\operatorname{argila}(<0,002 \mathrm{~mm})$ & 12 & 9 & 10 \\
\hline silte $(0,002-0,075 \mathrm{~mm})$ & 1 & 2 & 1 \\
\hline areia fina $(0,075-0,42 \mathrm{~mm})$ & 74 & 81 & 83 \\
\hline areia média $(0,42-2 \mathrm{~mm})$ & 13 & 8 & 6 \\
\hline \multicolumn{4}{|l|}{ Granulometria sem defloculante (\%) } \\
\hline $\operatorname{argila}(<0,002 \mathrm{~mm})$ & 12 & 1 & 7 \\
\hline silte $(0,002-0,075 \mathrm{~mm})$ & 2 & 14 & 3 \\
\hline areia fina $(0,075-0,42 \mathrm{~mm})$ & 73 & 77 & 85 \\
\hline areia média $(0,42-2 \mathrm{~mm})$ & 13 & 7 & 5 \\
\hline $\begin{array}{l}\text { Capacidade de troca catiônica, CTC } \\
(\mathrm{meq} / 100 \mathrm{~g})\end{array}$ & 0,56 & 0,40 & 0,41 \\
\hline Superfície específica, SE (m²/g) & 4,38 & 3,14 & 3,22 \\
\hline $\mathrm{pH}$ do solo em água $-\mathrm{RSS}=1: 5$ & 5,89 & 6,24 & 5,01 \\
\hline $\mathrm{pH}$ do solo em $\mathrm{KCl}-\mathrm{RSS}=1: 5$ & 4,44 & 4,84 & 4,28 \\
\hline$\Delta \mathrm{pH}\left(\mathrm{pH} \mathrm{KCl}-\mathrm{pH} \mathrm{H}_{2} \mathrm{O}\right)$ & $-1,45$ & $-1,40$ & $-0,73$ \\
\hline $\begin{array}{l}\text { Condutividade elétrica do extrato aquoso } \\
(\mathrm{mmho} / \mathrm{cm})\end{array}$ & 40 & 25,5 & 32,5 \\
\hline $\mathrm{pH}_{0}$ & 3,5 & 4,5 & 3,8 \\
\hline $\begin{array}{l}\text { Carga permanente líquida, } \mathrm{s}_{\mathrm{p}}(\mathrm{cmol} / \mathrm{kg}= \\
\mathrm{meq} / 100 \mathrm{~g})\end{array}$ & -1 & $-0,3$ & $-0,3$ \\
\hline
\end{tabular}

Nas figuras 4, 5 e 6 encontram-se resultados dos difratogramas de Raios X obtidos para os materiais inconsolidados estudados, em condição natural, tratada 
com etileno glicol e aquecida à $550^{\circ} \mathrm{C}$, respectivamente. Apresenta-se somente 1 resultado em função da se-

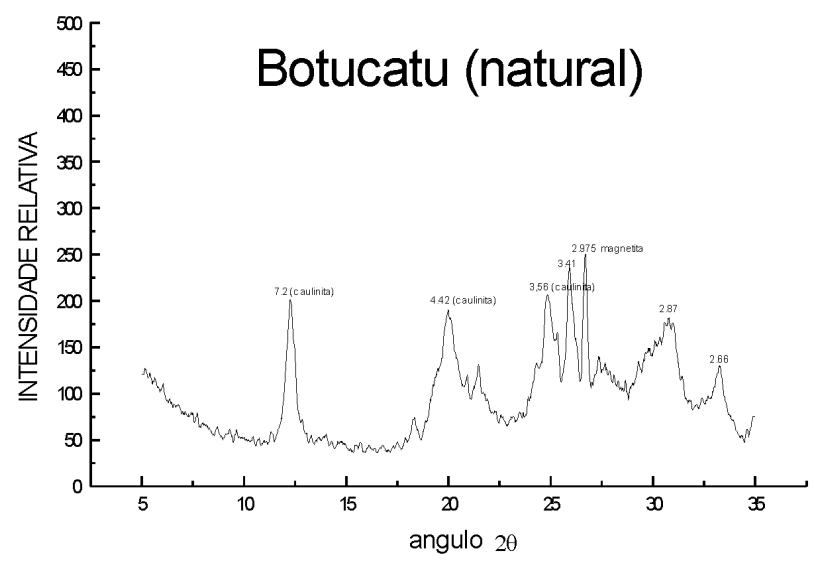

Figura 4 - Difratograma de raios Xcom amostra em condição natural.

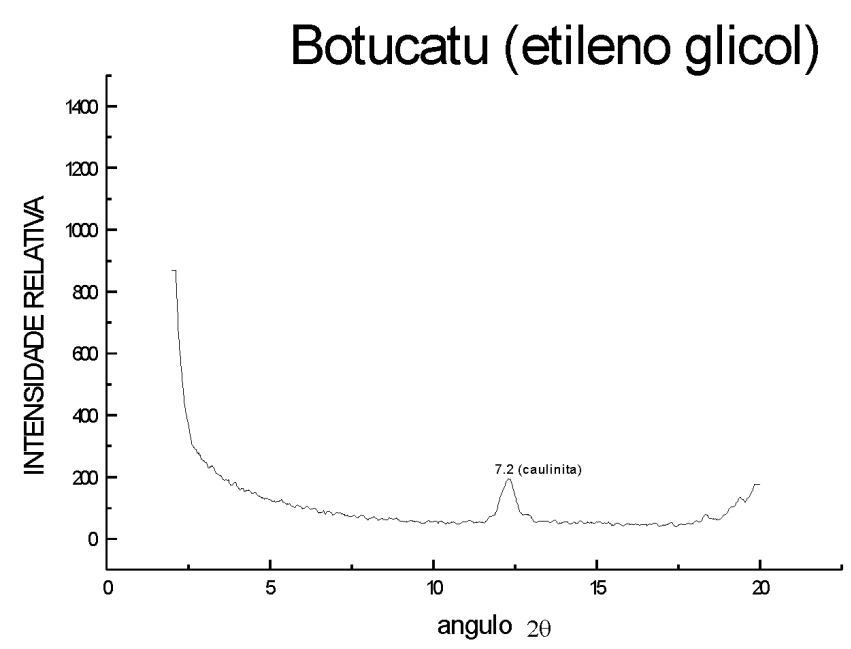

Figura 5 - Difratograma de raios X para amostra tratada com etileno glicol.

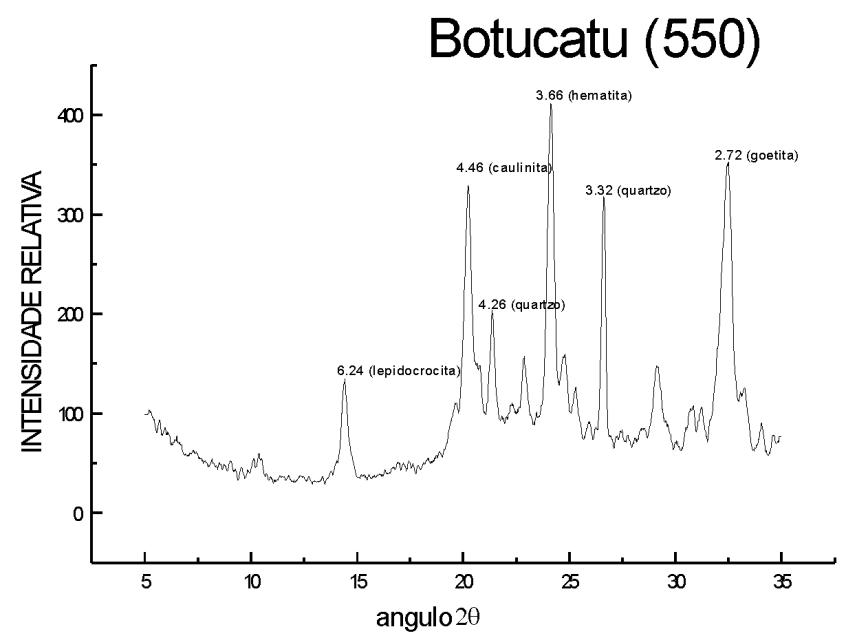

Figura 6 - Difratograma de raios $X$ para amostra submetida ao tratamento térmico a $550^{\circ} \mathrm{C}$. melhança qualitativa apresentada para os 3 locais.

$\mathrm{Na}$ figura 7 encontra-se fotos dos materiais geo-

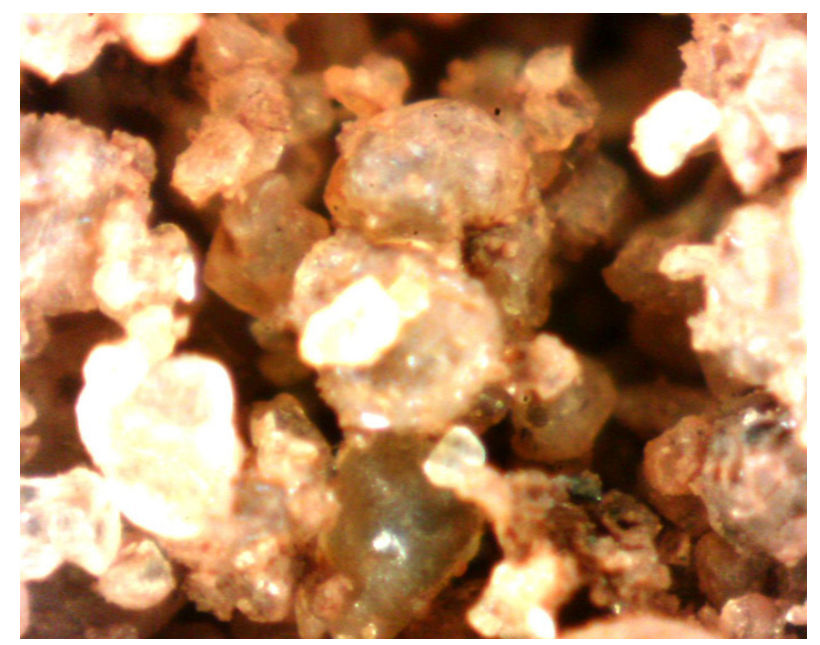

(a)

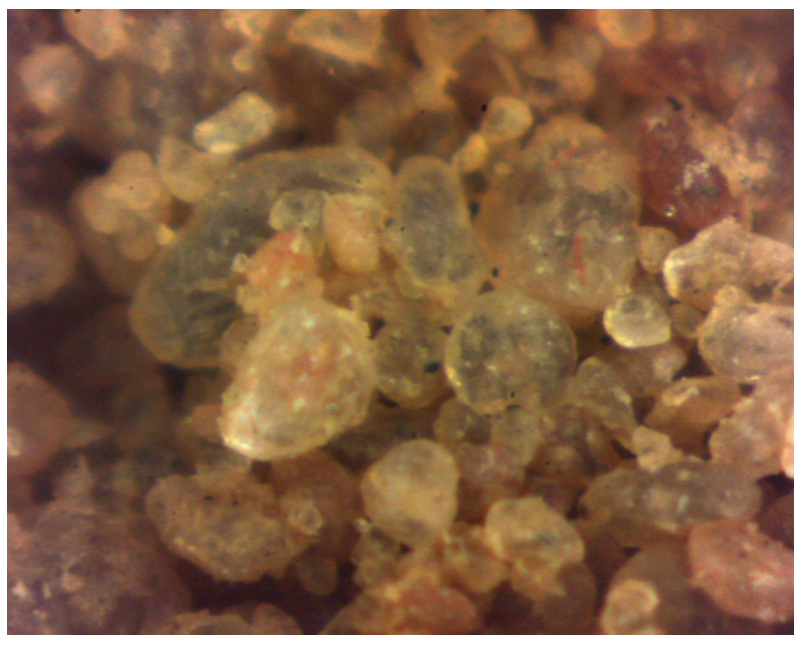

(b)

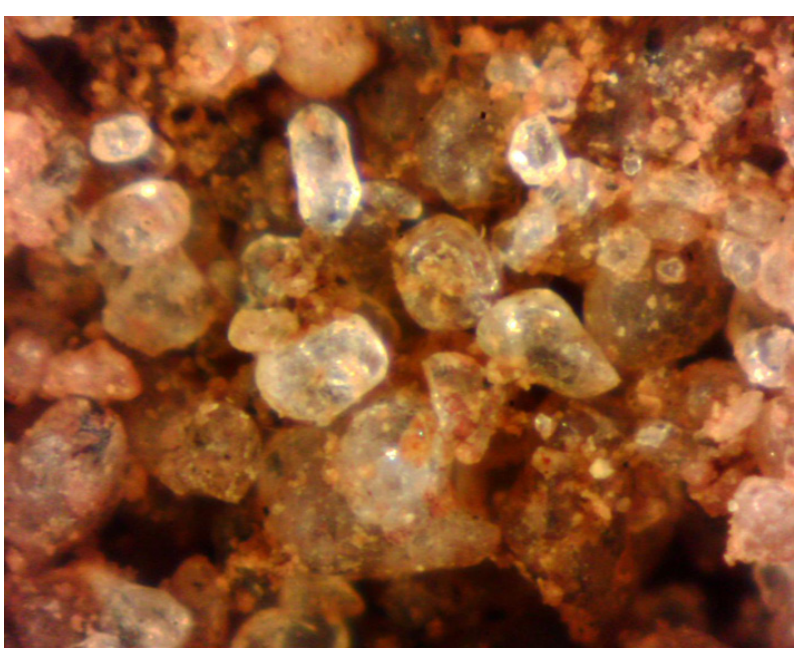

(c)

Figura 7 - Fotos dos materiais inconsolidados (1,6 mm X 1,2 mm): (a) Local 1; (b) Local 2; (c) Local 3. 
lógicos estudados onde se observa as cores amareladas e avermelhadas decorrentes dos hidróxidos e óxidos de Fe que recobrem as partículas, principalmente de quartzo.

Para os materiais inconsolidados dos 3 locais foram desenvolvidos ensaios de titulação para obtenção das curvas que permitem a obtenção do $\mathrm{pH}_{\mathrm{o}}$, conforme resultados apresentados nas figuras 8 a 10. A titulação foi feita para uma condição representando o branco e para 3 concentrações de $\mathrm{KCl}$.

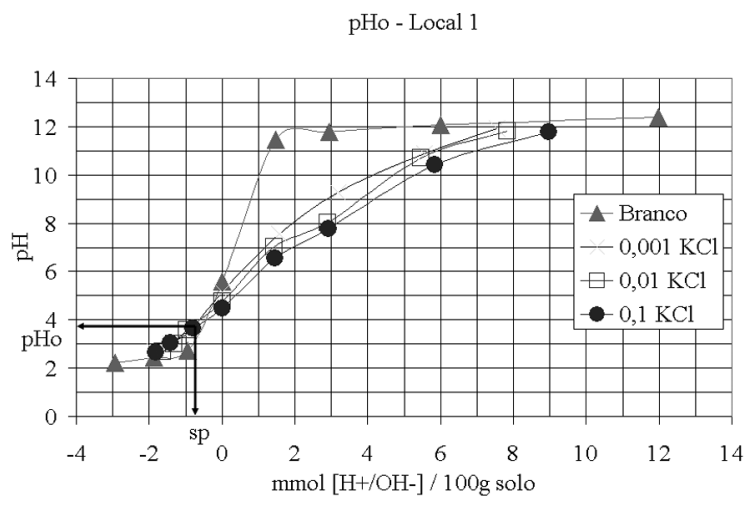

Figura 8 - Curvas resultantes do ensaio de titulação para obtenção do $\mathrm{pH}_{0}$ (ponto de carga zero) para local 1.

pHo - Local 2

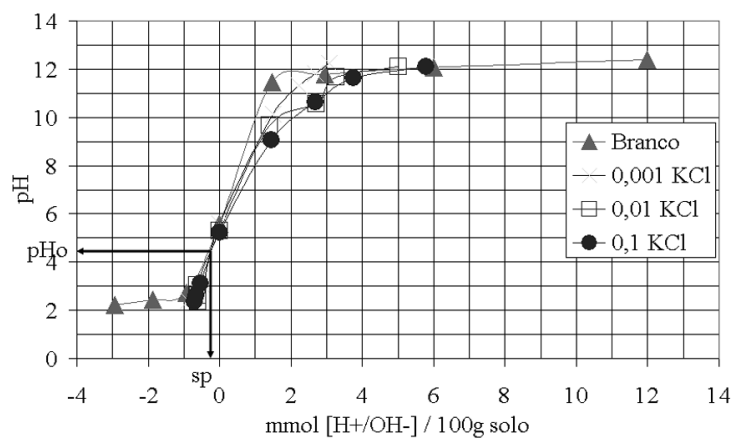

Figura 9 - Curvas resultantes do ensaio de titulação para obtenção do $\mathrm{pH}_{0}$ (ponto de carga zero) para local 2.

CARACTERIZAÇÃO DAS SOLUÇÕES MULTIONICAS As soluções para percolação foram preparadas com as concentrações apresentadas na tabela 2 . As soluções de cloretos de $\mathrm{Na}^{+}, \mathrm{K}^{+}, \mathrm{Zn}^{++}$e $\mathrm{Cu}^{++}$foram usadas em decorrência da freqüência destes íons na maioria das fontes de contaminação, sejam difusas ou pontuais. Buscou-se também considerar a competição entre pares $\left(\mathrm{Na}^{+}\right.$e $\left.\mathrm{K}^{+}\right)$e $\left(\mathrm{Zn}^{++}\right.$e Cu$\left.{ }^{++}\right)$, e entre os grupos.

RESULTADOS E DISCUSSÃO Considerando os valores de pH (Fig. 11a, b, c) e Eh (Fig. 11d, e, f) das

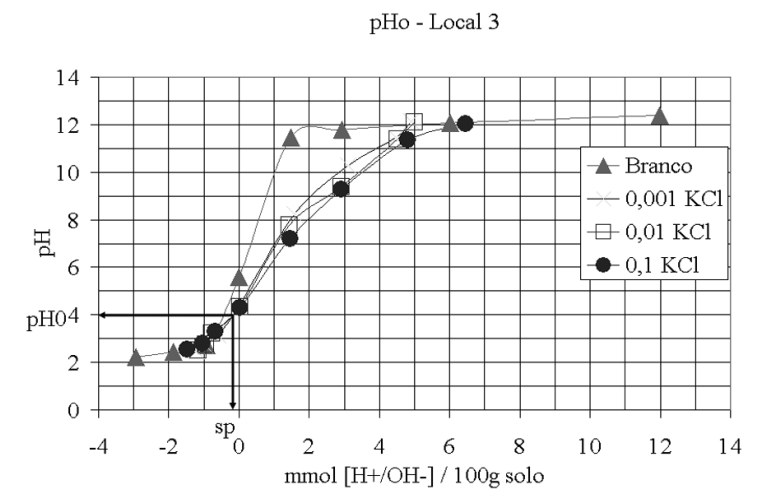

Figura 10 - Curvas resultantes do ensaio de titulação para obtenção do $\mathrm{pH}_{0}$ (ponto de carga zero) para local 3.

Tabela 2 - Concentrações das soluções.

\begin{tabular}{l|c|c|c|c|c|c|c|c|c}
\hline $\begin{array}{l}\text { Cátion/ } \\
\text { Solução }\end{array}$ & 1 & 2 & 3 & 4 & 5 & 6 & 7 & 8 & 9 \\
\hline $\begin{array}{l}\mathrm{Na}^{+} \\
(\mathrm{mg} / \mathrm{l})\end{array}$ & 51 & 76,5 & 102 & 127,5 & 153 & 178,5 & 204 & 229,5 & 255 \\
\hline $\mathrm{K}^{+}(\mathrm{mg} / \mathrm{l})$ & 49 & 73,5 & 98 & 122,5 & 147 & 171,5 & 196 & 220,5 & 245 \\
\hline $\begin{array}{l}\mathrm{Cu}^{++} \\
(\mathrm{mg} / \mathrm{l})\end{array}$ & 50,6 & 75,9 & 101,2 & 126,5 & 151,8 & 177,1 & 202,4 & 227,7 & 253 \\
\hline $\begin{array}{l}\mathrm{Zn} \\
(\mathrm{mg} / \mathrm{l})\end{array}$ & 52 & 78 & 104 & 130 & 156 & 182 & 208 & 234 & 260 \\
\hline $\begin{array}{l}\text { Total } \\
(\mathrm{mg} / \mathrm{l})\end{array}$ & 202,6 & 303,9 & 405,2 & 506,5 & 607,8 & 709,1 & 810,4 & 911,7 & 1013,0 \\
\hline
\end{tabular}

suspensões nas condições iniciais e finais para os três locais, nota-se as diminuições dos valores em relação àqueles das condições iniciais, com uma tendência dos valores finais se aproximarem do $\mathrm{pH}_{0}$ apresentados nas figuras 8,9 e 10 , o que mostra a baixa resilência destes materiais geológicos em termos desta propriedade. Os valores finais de potencial redox (Eh), de modo geral, também apresentaram uma tendência de queda, excetuando-se para aqueles correspondentes ao solo 1, que não refletiram um comportamento definido.

Os dados da figura 11 de $\mathrm{pH}$ e Eh permitem observar que a partir de uma concentração total de $500 \mathrm{mg} / 1$ ocorreram mudanças no comportamento das soluções tanto nas medidas iniciais quanto nas finais. Tal observação está refletida nos resultados de adsorção principalmente do $\mathrm{Zn}^{++}$e do $\mathrm{K}^{+}$, conforme apresentados nas figuras 12, 13 e 14, que apresentam os resultados obtidos pelo ensaio de equilíbrio em lote para os locais 1,2 e 3 , respectivamente.

Os resultados de Eh apresentados para os 3 materiais geológicos na figura $11(\mathrm{~d}, \mathrm{e}, \mathrm{f})$, permite observar que, de acordo com Baas Becking et al. (1960), os materiais geológicos, inicialmente, estão em uma con- 
LOCAL $1-\mathrm{pH}_{0}=3,8$

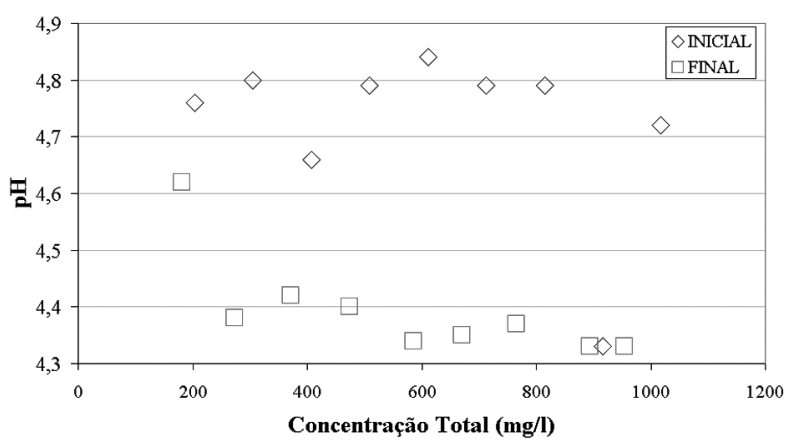

LOCAL $2-\mathrm{pH}_{0}=4,5$

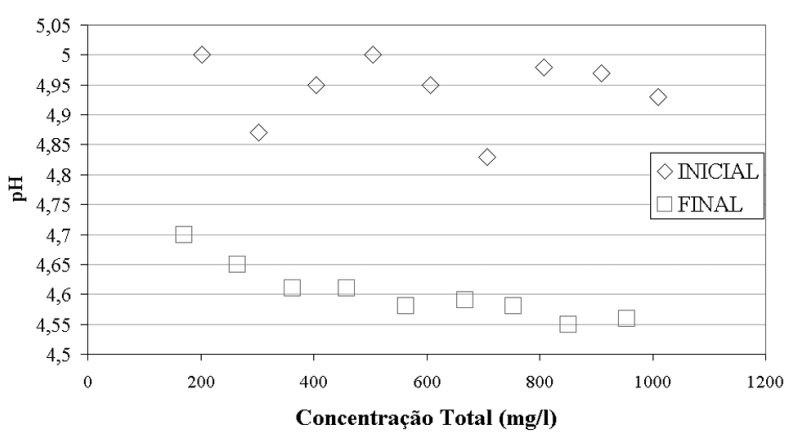

LOCAL 3 - $\mathrm{pH}_{0}=\mathbf{4 , 0}$

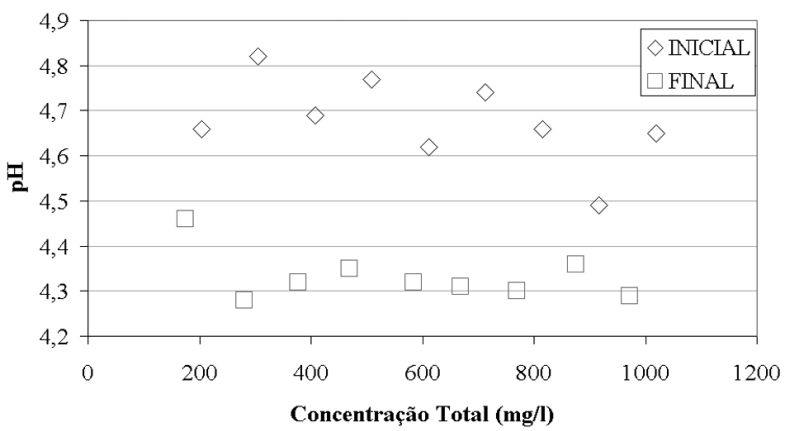

LOCAL 1

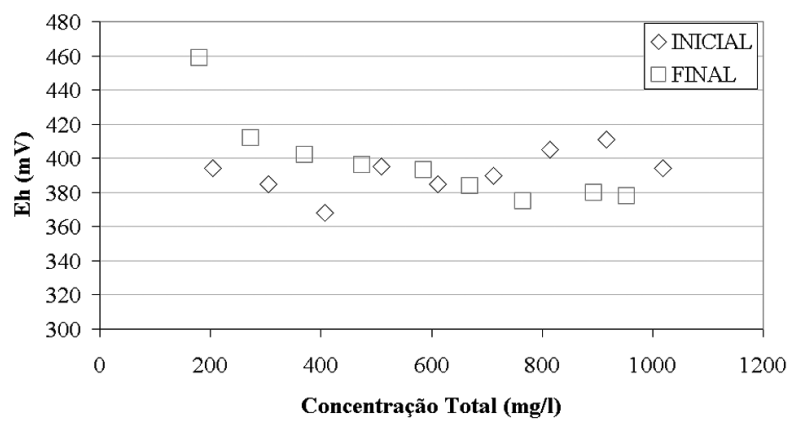

LOCAL 2

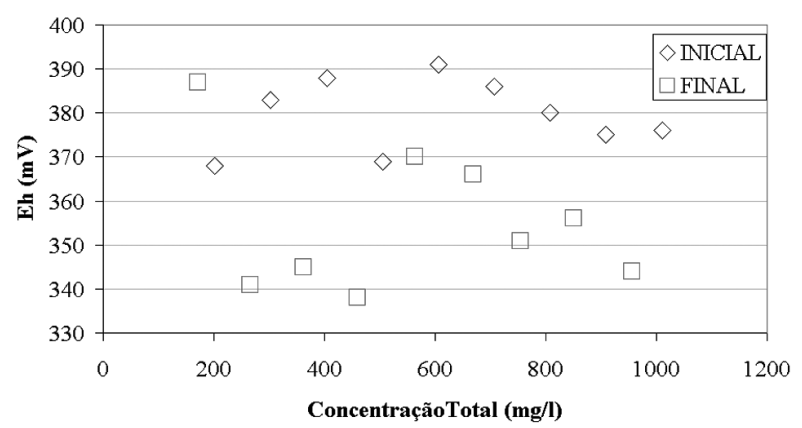

LOCAL 3

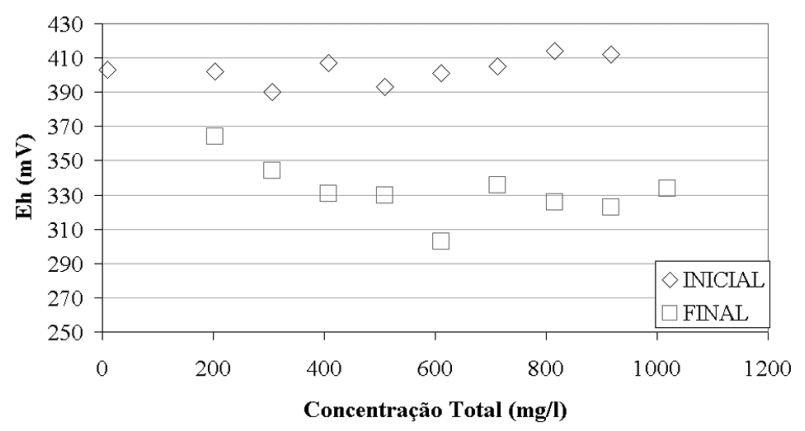

Figura 11 - Resultados de $\mathrm{pH}(a, b, c)$ e Eh $(d, e, f)$ das suspensões para a condição inicial e final do ensaio de equilibrio em lote (Batch test).

dição normal refletindo uma condição oxidante, e no final do ensaio os valores indicam uma condição de sazonalmente saturados, demonstrando que o ensaio refletiu uma possível condição de campo quando da instalação de uma fonte de poluentes.

As variações observadas nas isotermas experimentais do $\mathrm{Cu}^{++}$apresentadas nos gráficos A das figuras 12,13 e 14 é função da faixa de $\mathrm{pH}$ que os ensaios foram realizados (entre 4 e 5), que caracterizam como de maior variabilidade, frente aos diferentes constituintes dos materiais geológicos, representando as melhores condições para avaliar as condições de sorção. Sendo que em pH menores que 5 o $\mathrm{Cu}^{++}$e o $\mathrm{Zn}^{++}$apresentam menores condições de precipitação.

As isotermas de sorção obtidas experimentalmente e contidas nas partes A das figuras 12,13 e 14 são classificadas de acordo com Giles et al. $(1960,1974)$ como do tipo L (do tipo Langmuir) - subgrupo 2 para a do $\mathrm{Cu}^{++}$, dos tipos L e C, subgrupos 3 e 2, respectivamente, para o $\mathrm{Zn}^{++}$e $\mathrm{K}^{+}$. A partir desta classificação selecionaram-se os modelos matemáticos linear, de Freundlich e Langmuir I e II para a suas representações e obtenção dos parâmetros de sorção. $\mathrm{O}$ cátion $\mathrm{Na}^{+}$não sofreu o processo de sorção em nenhum dos 3 materiais geológicos, pois é de baixa competitividade quando comparado com os outros cátions da solução multicomponente. A partir da classificação das isotermas experimentais e seleção das equações matemáticas foram obtidos os parâmetros de sorção que se encontram na tabela 3 .

O modelo linear e de Freundlich mostraram-se mais adequados à parametrização do potássio $\left(\mathrm{K}^{+}\right)$para os solos 1 e 2, respectivamente. Para o solo 3, embora o 
Local 1

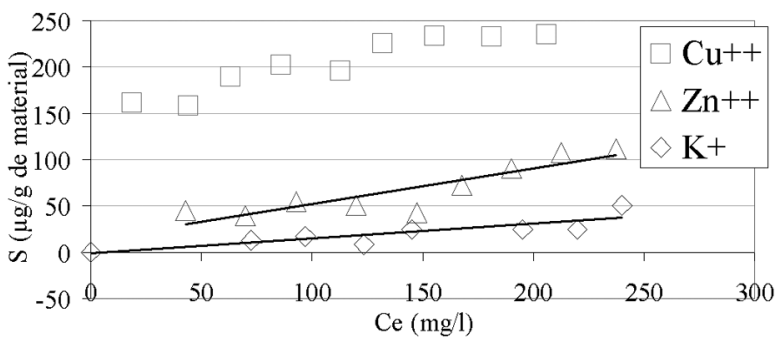

Freundlich

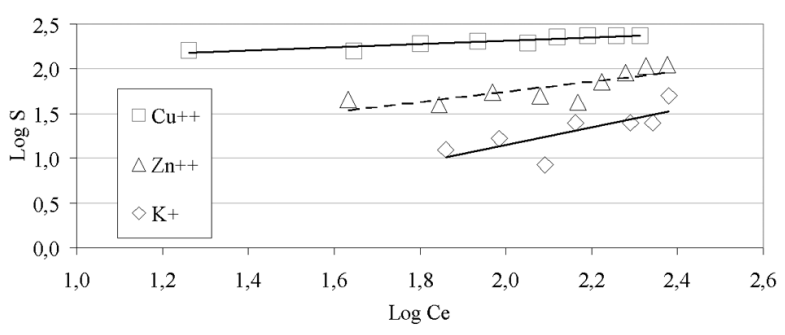

Langmuir I

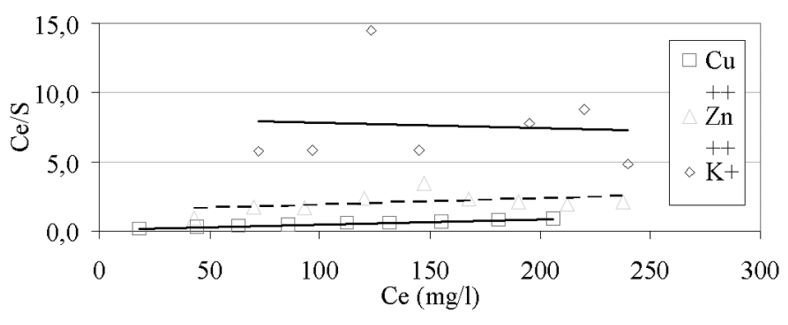

Langmuir II

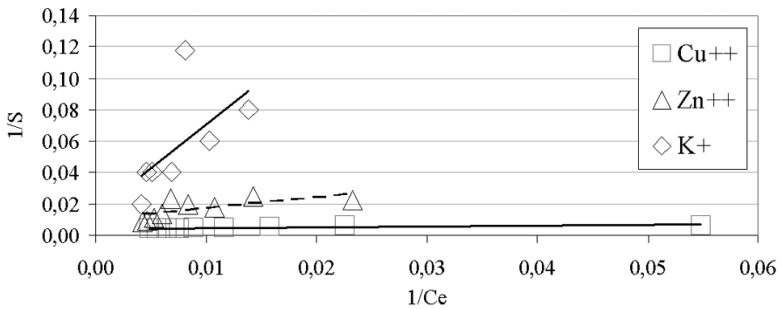

Figura 12 - Isotermas para o material do local 1. (a) resultados experimentais; (b) representação matemática de Freundlich; (c) representação matemática de Langmuir I; e (d) representação matemática de Langmuir II.

Local 2
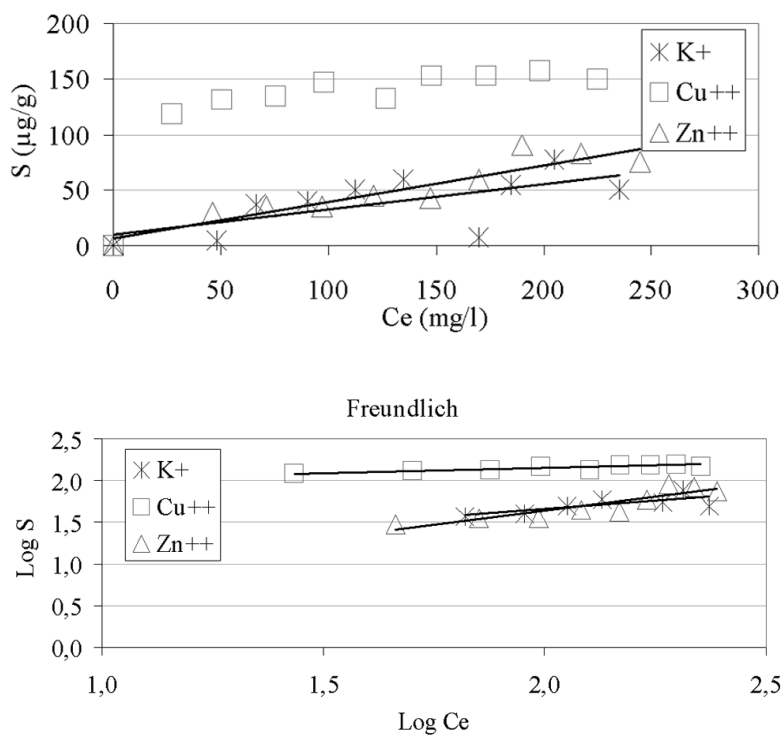

Langmuir I

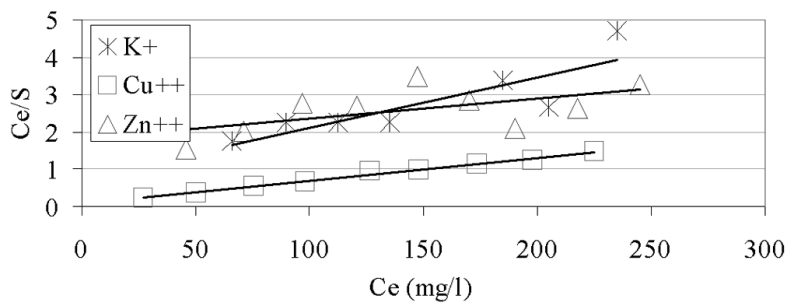

Langmuir II

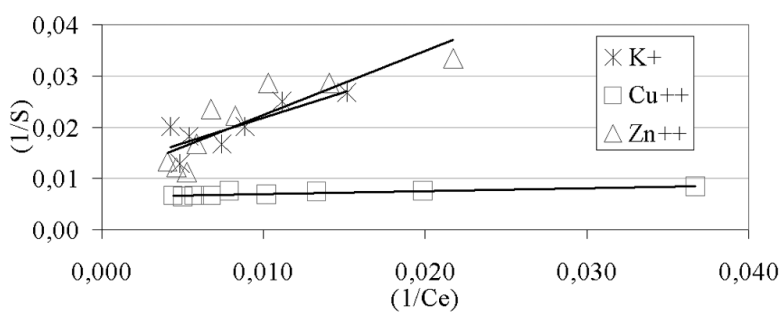

Figura 13 - Isotermas para o material do local 2. (a) resultados experimentais; (b) representação matemática de Freundlich; (c) representação matemática de Langmuir I; e (d) representação matemática de Langmuir II.

coeficiente de correlação $\left(\mathrm{R}^{2}\right)$ seja maior para o modelo de Langmuir II, o parâmetro $S_{m}$ encontrado apresentouse negativo, fato considerado fisicamente impossível. Sendo assim, o modelo linear e de Freundlich são os mais indicados para representar os fenômenos de sorção deste íon.

Os modelos Freundlich e Langmuir I se ajustaram bem aos resultados experimentais de sorção do cobre $\left(\mathrm{Cu}^{++}\right)$, com resultados melhores em relação à equação de Langmuir I.

Por outro lado, os fatores de correlação para o zinco $\left(\mathrm{Zn}^{++}\right)$indicam que o modelo linear descreve com maior veracidade os fenômenos de sorção deste íon para os solos 1 e 2, enquanto que para o solo 3 o modelo de Langmuir I mostrou-se mais adequado.

CONCLUSÃO Os valores de sorção obtidos nos dados experimentais estão em acordo com a previsão teórica 
Local 3

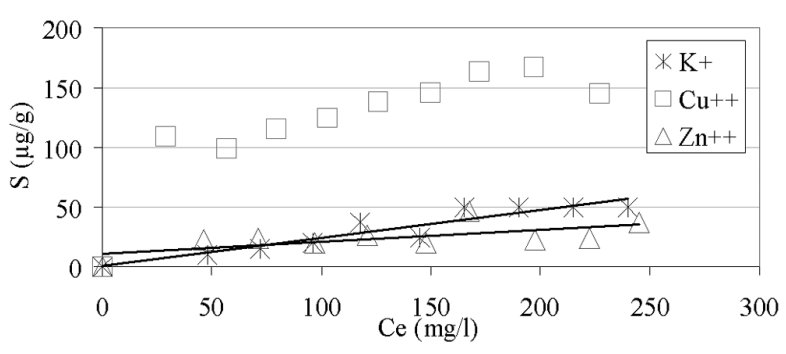

Freundlich

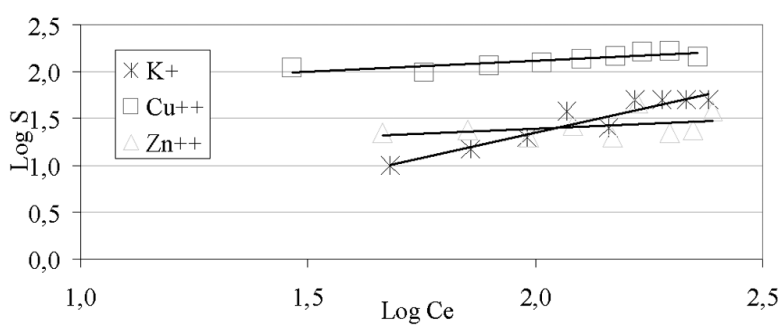

Langmuir I

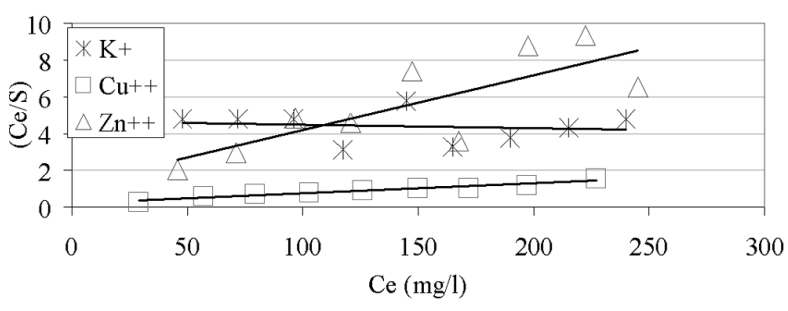

Langmuir II



Figura 14 - Isotermas para o material do local 3. (a) resultados experimentais; (b) representação matemática de Freundlich; (c) representação matemática de Langmuir I; e (d) representação matemática de Langmuir II.

para a faixa de $\mathrm{pH}$ e Eh estudada, sendo a competitividade dos íons na seguinte ordem: $\mathrm{Na}^{+}<\mathrm{K}^{+}<\mathrm{Zn}^{++}<\mathrm{Cu}^{++}$.

Observou-se que, com o aumento das concentrações dos cátions, o pH das soluções em estágio final aproximou-se dos valores de $\mathrm{pH}_{0}$, o que justifica as alterações apresentadas nas isotermas de sorção experimentais, principalmente para o $\mathrm{Cu}^{++}$e o $\mathrm{Zn}^{++}$.

Aplicando os modelos com os parâmetros obtidos para cada bateria de ensaio, foi possível determinar quais modelos mais adequadamente se ajustam aos valores experimentais de sorção. Os resultados indicaram que para o $\mathrm{K}^{+}$as equações matemáticas, linear, Freundlich e Langmuir I, apresentam bons resultados,
Tabela 3 - Parâmetros de sorção para os 3 materiais geológicos estudados obtidos pelas equações de Freundlich, Langmuir I e Langmuir II.

\begin{tabular}{|c|c|c|c|}
\hline & Local 1 & Local 2 & Local 3 \\
\hline $\mathrm{pH}$ & $4.33--4.84$ & $4.55--4.98$ & $4.28--4.82$ \\
\hline Eh (mV) & $368--459$ & $338--391$ & $303--414$ \\
\hline $\mathrm{CE}(\mathrm{mmho} / \mathrm{cm})$ & $737--3250$ & $744--3260$ & $714--3150$ \\
\hline \multicolumn{4}{|l|}{ COBRE $-\mathrm{Cu}^{++}$} \\
\hline \multicolumn{4}{|l|}{ Freundlich } \\
\hline $\mathrm{R}^{2}$ & 0,8596 & 0,8021 & 0,7447 \\
\hline $\mathrm{K}_{\mathrm{f}}\left(\mathrm{cm}^{3} / \mathrm{g}\right)$ & 88,1252 & 80,0571 & 43,7623 \\
\hline $\mathrm{N}$ & 0,1842 & 0,1219 & 0,2364 \\
\hline \multicolumn{4}{|l|}{ Langmuir } \\
\hline $\mathrm{R}^{2}$ & 0,9878 & 0,9904 & 0,9528 \\
\hline $\mathrm{S}_{\mathrm{m}}(\mathrm{mg} / \mathrm{g})$ & 256,4103 & 161,2903 & 181,8182 \\
\hline $\mathrm{b}\left(\mathrm{cm}^{3} / \mathrm{mg}\right)$ & 0,0456 & 0,0786 & 0,0279 \\
\hline \multicolumn{4}{|l|}{ Langmuir II } \\
\hline $\mathrm{R}^{2}$ & 0,6457 & 0,7822 & 0,5474 \\
\hline $\mathrm{S}_{\mathrm{m}}(\mathrm{mg} / \mathrm{g})$ & 227,2727 & 156,25 & 156,25 \\
\hline $\mathrm{b}\left(\mathrm{cm}^{3} / \mathrm{mg}\right)$ & 0,1081 & 0,109 & 0,0581 \\
\hline \multicolumn{4}{|l|}{$\mathrm{ZINCO}-\mathrm{Zn}^{++}$} \\
\hline \multicolumn{4}{|l|}{ Linear } \\
\hline $\mathrm{R}^{2}$ & 0,8462 & 0,848 & 0,1776 \\
\hline $\mathrm{K}_{\mathrm{d}}\left(\mathrm{cm}^{3} / \mathrm{g}\right)$ & 0,464 & 0,3661 & 0,163 \\
\hline \multicolumn{4}{|l|}{ Freundlich } \\
\hline $\mathrm{R}^{2}$ & 0,6303 & 0,8093 & 0,1632 \\
\hline $\mathrm{K}_{\mathrm{f}}\left(\mathrm{cm}^{3} / \mathrm{g}\right)$ & 4,0179 & 1,9829 & 9,3735 \\
\hline $\mathrm{N}$ & 0,5703 & 0,6683 & 0,2086 \\
\hline \multicolumn{4}{|l|}{ Langmuir } \\
\hline $\mathrm{R}^{2}$ & 0,1968 & 0,3442 & 0,6267 \\
\hline $\mathrm{S}_{\mathrm{m}}(\mathrm{mg} / \mathrm{g})$ & 222,2222 & 185,1852 & 33,4448 \\
\hline $\mathrm{b}\left(\mathrm{cm}^{3} / \mathrm{mg}\right)$ & 0,0031 & 0,003 & 0,0246 \\
\hline \multicolumn{4}{|l|}{ Langmuir II } \\
\hline $\mathrm{R}^{2}$ & 0,4458 & 0,767 & 0,1172 \\
\hline $\mathrm{S}_{\mathrm{m}}(\mathrm{mg} / \mathrm{g})$ & 94,3396 & 101,0101 & 28,8184 \\
\hline $\mathrm{b}\left(\mathrm{cm}^{3} / \mathrm{mg}\right)$ & 0,0156 & 0,008 & 0,0594 \\
\hline \multicolumn{4}{|l|}{ POTÁSSIO - K ${ }^{+}$} \\
\hline \multicolumn{4}{|l|}{ Linear } \\
\hline $\mathrm{R}^{2}$ & 0,7488 & 0,3841 & 0,8832 \\
\hline $\mathrm{K}_{\mathrm{d}}\left(\mathrm{cm}^{3} / \mathrm{g}\right)$ & 0,1516 & 0,2867 & 0,2376 \\
\hline \multicolumn{4}{|l|}{ Freundlich } \\
\hline $\mathrm{R}^{2}$ & 0,5745 & 0,5579 & 0,8966 \\
\hline $\mathrm{K}_{\mathrm{f}}\left(\mathrm{cm}^{3} / \mathrm{g}\right)$ & 0,1566 & 7,4131 & 0,1558 \\
\hline $\mathrm{N}$ & 0,9777 & 0,3951 & 1,0815 \\
\hline \multicolumn{4}{|l|}{ Langmuir } \\
\hline $\mathrm{R}^{2}$ & 0,0061 & 0,7333 & 0,0257 \\
\hline $\mathrm{S}_{\mathrm{m}}(\mathrm{mg} / \mathrm{g})$ & $-243,9024$ & 73,5294 & $-476,1905$ \\
\hline $\mathrm{b}\left(\mathrm{cm}^{3} / \mathrm{mg}\right)$ & $-0,0005$ & 0,018 & $-0,0004$ \\
\hline \multicolumn{4}{|l|}{ Langmuir II } \\
\hline $\mathrm{R}^{2}$ & 0,3608 & 0,686 & 0,9531 \\
\hline $\mathrm{S}_{\mathrm{m}}(\mathrm{mg} / \mathrm{g})$ & 69,9301 & 84,7458 & $-222,2222$ \\
\hline $\mathrm{b}\left(\mathrm{cm}^{3} / \mathrm{mg}\right)$ & 0,0025 & 0,0118 & $-0,0009$ \\
\hline SÓDIO - $\mathrm{Na}^{+}$ & $\mathrm{SN}$ & SN & $\mathrm{SN}$ \\
\hline
\end{tabular}

Legenda: $K_{f}$ - coeficiente de partição de Freundlich $\left[\mathrm{cm}^{3} / \mathrm{g}\right], N$ - coeficiente exponencial de Freundlich., $S$ - quantidade máxima de soluto adsorvida pelo solo $[\mu \mathrm{g} / \mathrm{g}], b$ - constante de adsorção relacionada à energia de ligação $\left[\mathrm{cm}^{3} / \mathrm{mg}\right], \mathrm{R}^{2}, \mathrm{pH}$ - Potencial hidrogeniônico, Eh - Potencial redox, CE - Condutividade elétrica, e SN - Sem sorção. 
enquanto para o $\mathrm{Cu}^{++}$o modelo de Langmuir I prevalece sobre os outros modelos. Para o $\mathrm{Zn}^{++}$as equações de Freundlich e linear mostraram boa concordância com os dados experimentais.

Nenhum dos materiais dos 3 locais adsorveu o íon sódio $\left(\mathrm{Na}^{+}\right)$, o que provavelmente se deve ao fato da utilização de uma solução multi-espécie no ensaio, resultando num ambiente de competição entre os íons em que prevalecem aqueles de maior afinidade química.

Ademais, é importante ressaltar que os ensaios de equilíbrio em lote consideram uma condição potencial de sorção, uma vez que todas as partículas do solo entram em contato com a solução contaminante, o que permite uma modelação numérica mais adequada porque o limite superior encontra-se parametrizado. Além, desta situação é possível utilizar as diferentes representações matemáticas diretamente em modelos de transporte de poluentes em meio poroso; assim como obter o fator de retardamento para diferentes valores de massa específica aparente seca de campo e de umidade volumétrica, no caso de estudos de campo e monitoramentos, como também em termos de propor medidas de controle.

Agradecimentos Agradecemos ao Conselho Nacional de Desenvolvimento Científico e Tecnológico (CNPq) pela concessão da bolsa de estudo e pelo auxilio Processo $N^{\circ}$ 472091/2006 - 9, e à Fundação de Amparo à Pesquisa do Estado de São Paulo (FAPESP) pelo auxilio Projeto FAPESP N ${ }^{\circ}$ 06/59445-8.

\section{Referências}

ASSOCIAÇÃO BRASILEIRA DE NORMAS TÉCNICAS (ABNT) 1984. (MB 32) NBR 7181 Solo - Análise Granulométrica.

Appelo C.A.J. \& Postma D. 1994. Geochemistry, Groundwater and Pollution. Rotterdam, Balkema, 536p.

Baas Becking L.G.M., Kaplan I.R., Moore D. 1960. Limits of the natural environment in terms of plant and oxidationreduction potentials. J. Geo. Phys., 68:243-284.

Barizon R.R.M., Lavorenti A., Regitano J.B., Tornisielo V.L. 2005. Sorção e dessorção do imazaquin em solos com diferentes características granulométricas, químicas e mineralógicas. R. Bras. Ci. Solo, 29:695-703.

Bradbury M.H. \& Baeyens B. 1999. Modelling the sorption of $\mathrm{Zn}$ and $\mathrm{Ni}$ on Ca-montimorillonite. Geochm. Cosmochim. Acta, 63:325-336.

Camargo O.A., Moniz A.C., Jorge, J.A., Valadares J.M.A.S. 1986. Métodos de Análise Química, Mineralógica e Física de Solos do Instituto Agronômico de Campinas. Boletim Técnico IAC (106), Campinas, 95p.

Davis J. A. \& Leckie J. O. 1978. Surface Ionization and Complexation at the Oxide/Water Interface II. Surface Properties of Amorphous Iron Oxyhydroxide and Adsorption of Metal Ions. Journal of Colloid and Interface Science, 67(1):90-107.

Davis J. A., James R.O., Leckie J.O. 1978. Surface ionization and complexation at the oxide/water interface. I. Computation of electrical double layer properties in simple electrolytes. J. Colloid Interface Sci., 63:480499.

Elzinga E.J., Van Grinsven J.J.M., Swartjes F.A. 1999. General purposes isotherms for cadmium, copper and zinc in soils. Eur. J. Soil Sci., 50:139-149.

Freeze R.A. \& Cherry J.A. 1979. Groundwater. Prentice Hall, Inc., 604 p.

Giles C. H., MacEwan T. H., Nakhwa S. N., Smith, D. (1960). Studies in adsorption. Part XI. A system of classification of solution adsorption isotherms and its use in the diagnosis of adsorption mechanisms and in measurements of specific surface areas of solids. Journal of Chemical Society, 3973-3993.
Giles C.H., Smith D.Y., Huitson A. 1974. A General Treatment and Classification of the Solute Adsorption Isotherm. I. Theoretical Journal of Colloid and Interface Science, 47(3):755-765.

Goldberg S. 1998. Ion adsorption at soil particle-solution interface: modeling and mechanisms. In: Huang P.M., Senesi N., Buffle J. (eds.) Structure and Surface Reactions of Soil Particles. New York, Wiley, p. 377412.

Hinz C. 2001. Description of sorption data with isotherm equations. Geoderma, 99:225-243

Hinz C., Gaston L.A., Selim H.M. 1994. Effect of sorption isotherm type on predictions of solute mobility in soil. Water Resour. Res., 30:3013-3021.

Leite A.L. 2001. Migração de Íons Inorgânicos em Alguns Solos Tropicais, com Enfase nos Processos de Sorção e Difusão Molecular. Tese de Doutoramento, Escola de Engenharia de São Carlos, Universidade de São Paulo, $254 \mathrm{p}$.

Mckenzie R. 1980. The adsorption of lead and other heavy metals on oxides of Mn and Fe. Austr. J. Soil Res., 18:6173.

Murali V. \& Aylmore L.A.G. 1983. Competitive adsorption during solute transport in soils: 1.Mathematical models. Soil Sci., 135:143-150.

Nascimento C.W.A. \& Fontes R.L.F. 2004. Correlação entre características de latossolos e parâmetros de equações de adsorção de cobre e zinco. Rev Bras. Ci. Solo, 28:965971.

Pierangeli M.A.P., Guimarães G.L.R., Curi N., Costa E.T.S., Lima J.M., Marques J.J.G.S.M., Figueiredo L.F.P. 2007. Comportamento sortivo, individual e competitivo, de metais pesados em latossolos com mineralogia contrastante. R. Bras. Ci. Solo, 31:819-826.

Roy W.R., Krapac I.G., Chou S.F.J., Griffin R.E. 1992. Batch-type Procedures for Estimating Soil Adsorption of Chemicals. Technical Resource Document, EPA/530/ SW-87/006-F, 101p.

Santos L.V., Polivanov H., Alamino R.C.J., Silva V.H.G. 2006. Adsorção de Cloreto e Potássio em Solos 
Tropicais. Anuário do Instituto de Geociências - UFRJ, 29(2):101-121.

Schindler P.W. \& Stumm W. 1987. The surface chemistry of oxides, hydroxides and oxide minerals. In: Stumm W. (ed.) Aquatic surface chemistry. New York, Wiley and Sons, p. 83-110.

Singh P. \& Uehara G. 1988. Eletrochemistry of the DoubleLayer: Principles and Applications to Soils. In: Sparks D.L. (ed.) Soil Physical Chemistry. Boca Raton: CRC Press, Inc. Cap.1, p.1-38.

Souza R.S., Chaves L.H.G., Fernandes J.D. 2006. Adsorção de zinco e sua relação com características de solos do Estado da Paraíba. Revista Brasileira de Ciências Agrárias, 1:1-6.

Stumm W., Kummert R., Sigg L. 1980. A ligand exchange model for the adsorption of inorganic and organic ligands at hydrous oxide interfaces. Croat. Chem. Acta, 53:291-312

Van Der Zee S.E.A.T.M., Van Riemsdijk W.H. 1987. Transport of reactive solute in spatially variable soil systems. Water Resour. Res., 23:2059-2069.

Van Riemsdijk W.H., Bolt G.H., Koopal L.K., Blaakmeer J. 1985. Electrolyte adsorption on heterogeneous surfaces: adsorption models. J. Colloid Interface Sci., 109:219228.

Wang F.Y., Chen J.S., Forsling W. 1997. Modeling sorption of trace metals on natural sediments by surface complexation model. Env. Sci. Technol., 31:448-453.

Yong R.N., Mohamed A.M.O., Warkentim B.P. 1992. Principles of Contaminant Transport in Soils. Amsterdam, Elsevier, 327 p.

Zachara J.M., Cowan C.E., Resch C.T. 1991. Sorption of divalent metals on calcite. Geochmist. Cosmoch. Acta, 55:1549-1562.

Zuquette L.V., Silva Jr. E.M., Garcia A. 2008. Aspectos de Sorção para os Materiais Inconsolidados da Região de São Carlos (SP), Brasil. Revista da Escola de Minas, Ouro Preto, 61(2):219-230.

Zuquette L. V., Palma J. B., Pejon O. J. 2009. Methodology to assess groundwater pollution conditions (current and pre-disposition) in the São Carlos and Ribeirão Preto regions, Brazil. Bulletin of Engineering Geology and the Environment, 68(1):117-136.

Manuscrito ID 12873

Submetido em 20 de novembro de 2008 Aceito em 17 de agosto de 2009 